University of Nebraska - Lincoln

DigitalCommons@University of Nebraska - Lincoln

Faculty Papers and Publications in Animal

Science

Animal Science Department

January 1978

\title{
FACTORS AFFECTING TWINNING AND EFFECTS OF TWINNING IN HOLSTEIN DAIRY CATTLE
}

\author{
R. A. Cady \\ Cornell University \\ L. Dale Van Vleck \\ University of Nebraska-Lincoln, dvan-vleck1@unl.edu
}

Follow this and additional works at: https://digitalcommons.unl.edu/animalscifacpub

Part of the Animal Sciences Commons

Cady, R. A. and Van Vleck, L. Dale, "FACTORS AFFECTING TWINNING AND EFFECTS OF TWINNING IN HOLSTEIN DAIRY CATTLE" (1978). Faculty Papers and Publications in Animal Science. 336.

https://digitalcommons.unl.edu/animalscifacpub/336

This Article is brought to you for free and open access by the Animal Science Department at DigitalCommons@University of Nebraska - Lincoln. It has been accepted for inclusion in Faculty Papers and Publications in Animal Science by an authorized administrator of DigitalCommons@University of Nebraska - Lincoln. 


\title{
FACTORS AFFECTING TWINNING AND EFFECTS OF TWINNING IN HOLSTEIN DAIRY CATTLE'
}

\author{
R. A. Cady and L. D. Van Vleck \\ Cornell University ${ }^{2}$, Ithaca, NY 14853
}

\begin{abstract}
SUMMARY
Data were obtained from 23,978 calving records collected by the Eastern Artificial Insemination Cooperative's Calving Survey. The survey information included breed, parity and size of dam, date of breeding and birth, identification of sire and maternal grandsire, sex, size, and vigor of calf, and difficulty of birth. Due to small numbers of records for non-Holstein breeds, only Holstein records were used in the analyses. As parity increased, the incidence of twinning increased $(P<.05)$. Month of birth (conception) and the size of dam measured within parity did not affect the twinning rate. The heritability of twinning, estimated using the genetic covariance between paternal half-sibs was .05 over all parities and within parity was $.06, .03$, and .03 for the first, second and third parities, respectively. Length of gestation for twins was 5 days less $(P<.05)$ than for singles. In addition, twins were smaller and weaker, and their birth was accompanied by more dystocia than monoparous calves $(\mathrm{P}<.05)$. Neonatal mortality was four times higher $(P<.05)$ for twins as compared to single births. In view of these facts, it does not appear that selection programs designed to increase twinning rates would be desirable for Holstein dairy cattle.
\end{abstract}

(Key Words: Dystocia, Twinning, Gestation, Parity, Neonatal.)

\section{INTRODUCTION}

Interest in the possibility of selecting for an increased rate of twinning in cattle has been rekindled. A beef cow can wean more total calf weight by raising twins. Dairy cows may give more milk in the lactation resulting from a twin

\footnotetext{
'The contribution of data and financial support by Eastern Artificial Insemination Cooperative for this work is gratefully acknowledged.

${ }^{2}$ Department of Animal Science.
}

birth (Syrstad, 1974a). In addition, increased frequency of twinning would increase the potential for obtaining more progeny from a genetically-superior female, thereby allowing those females to play a larger role in a selection program.

Hendy and Bowman (1970) and Rutledge (1975) have done extensive reviews of past literature published on twinning. They seem to be optimistic about the advantages twinning offers in spite of the problems that twinning causes. However, most of the previous work reviewed was done using small sample sets, and the authors of both reviews advocated further research. Johansson et al. (1974) have done extensive work with large amounts of data from European dairy breeds to investigate calses of twinning. They are also optimistic about increasing the twinning rate of dairy cattle in light of the review by Hendy and Bowman (1970).

The question that should be answered fully before going ahead and increasing the twinning rate in cattle, whether it be through genetic selection or the administration of hormones, is whether the advantages can profitably overcome the problems that have been discussed in previous literature (Hendy and Bowman, 1970; Rutledge, 1975; Cady, 1977) if these problems are important.

The purpose of this research was to investigate the importance of fixed factors that affect twinning rates as well as the effects twins have on calving traits such as dystocia.

\section{METHODS AND MATERIALS}

Data for this study were provided by Eastern Artificial Insemination Cooperative, Inc. from their calving difficulty survey. The survey was conducted by distributing questionnaires to member dairymen and asking them, at the time of the calving, to fill in information about each calving that occurred on their farm. The information asked for was: herd identification, 
TABLE 1. INCIDENCE OF MULTIPLE BIRTHS

\begin{tabular}{llllll}
\hline & $\begin{array}{l}\text { Total } \\
\text { births }\end{array}$ & $\begin{array}{l}\text { Multiple } \\
\text { births } \\
(\%)\end{array}$ & $\begin{array}{l}\text { Twins } \\
\text { (no.) }\end{array}$ & $\begin{array}{l}\text { Triplets } \\
\text { (no.) }\end{array}$ & $\begin{array}{l}\text { Quad- } \\
\text { ruplets } \\
\text { (no.) }\end{array}$ \\
\hline Holstein & 21,174 & 4.75 & 997 & 7 & 1 \\
Guernsey & 300 & 2.33 & 7 & 0 & 0 \\
Jersey & 545 & 1.83 & 6 & 0 & 0 \\
Ayrshire & 229 & 2.62 & 2 & 0 & 0 \\
Brown Swiss & 49 & 4.08 & & 0 & 0 \\
\hline
\end{tabular}

identification of the dam, sire and maternal grandsire of the calf, breed of dam, dates of breeding and calving, sex of calf, parity number and subjective evaluations by the dairymen of dam size as compared to her contemporaries, size of calf, difficulty of birth and vigor of calf. To obtain uniform reporting of these subjective measurements, dairymen were asked to score the traits using a code that was provided. Dam size was scored as (1) large, (2) medium, (3) small. Calf size was classified (1) very small, (2) small, (3) average, (4) large, (5) very large. Dystocia was classified as (1) no problem, (2) slight difficulty, (3) needed assistance, (4) considerable force, (5) extreme difficulty. Vigor was classified as (1) healthy, (2) weak, (3) died within 24 hours. In addition, space was provided to allow the dairymen to add any comments that they felt were pertinent to the calving. They were asked specifically to identify multiple births, abnormal calves and abortions.

There were 23,978 records received from September 1974 to August 1975, which included information on the five major dairy breeds in the United States. Editing of the data was done separately for each analysis. A record was discarded only when required information for a specific analysis was not provided; therefore, the editing for each analysis was different. Separate editing was done to preserve as much information as possible because the overall twinning rate was less than $5 \%$, resulting in few twins even with the large data set. When the records were edited on all important missing data at once, the number of records was reduced by one-third. The differences for parameters estimated in different analyses were less than $5 \%$ estimation, so the effect of editing was minimal and did not influence any of the conclusions.

Due to the small number of births in the non-Holstein breeds (table 1), all further analyses used only Holstein records to avoid confounding with breed effects. Triplets and quadruplets were not used in any calculations unless results refer to multiple births.

Twin births were scored as 1 and monoparous births were scored as 0 in this study.

TABLE 2. EFFECTS OF TWINNING RATE BY ANALYSIS OF VARIANCE AND CHI-SQUARE TESTS

\begin{tabular}{|c|c|c|c|c|c|}
\hline Source & df & $F$ & $\begin{array}{l}\text { No. of } \\
\text { tables }\end{array}$ & $\begin{array}{l}\text { Chi- } \\
\text { square }\end{array}$ & Normal \\
\hline Month & 11 & 1.43 & 1 & 18.35 & $\ldots$ \\
\hline Parity & 2 & $24.82^{*}$ & 1 & $161.61 *$ & $\cdots$ \\
\hline$M \times P$ & 22 & 1.41 & 3 & $\ldots$ & $7.08^{*}$ \\
\hline Dam size:parity & 6 & .73 & 3 & $\cdots$ & 1.71 \\
\hline$M \times D: P$ & 66 & $1.51^{*}$ & 9 & $\ldots$ & $12.75^{*}$ \\
\hline Dam sizea & 2 & $\ldots$ & 1 & $7.38^{*}$ & $\ldots$ \\
\hline Residual & 20402 & $.001^{b}$ & $\ldots$ & $\ldots$ & $\cdots$ \\
\hline
\end{tabular}

\footnotetext{
${ }^{a}$ Ignoring nesting within parity.

${ }^{b}$ Residual mean square.

$*$ P $<.05$.
} 


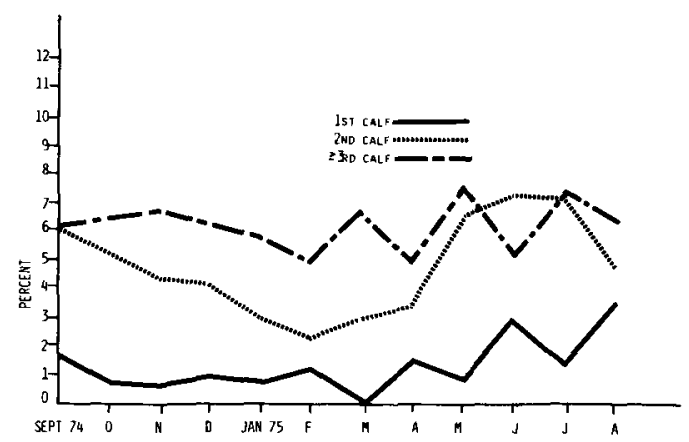

Figure 1. Percentage of twin births by parity and month born.

Analysis of variance of unweighted subclass means was used to determine which fixed factors were significant. The analytical model used is outlined in table 2. All factors except error were considered to be fixed effects.

Observations scored as 1 or 0 are not normally distributed, which violates a prerequisite for the analysis of variance. Therefore, the factors tested in the analysis of variance were also tested using chi-square goodness-of-fit tests and a variation of the chi-square test for multiple contingency tables as described by Snedecor and Cochran (1967). The test statistic for the multiple contingency table case is compared to the normal table. The formula for the statistic is:

$$
\text { test statistic }=\sum_{i=1}^{\mathrm{g}} \quad \chi_{i} / \sqrt{\mathrm{g}}
$$

where: $\chi_{i}=$ square root of $\chi^{2}$ value

$$
\mathrm{g}=\text { number of tables. }
$$

The incidence of monozygous twins among like-sexed twins was calculated using a maxi- mum-likelihood function derived by Bonnier (1946). The formula used was:

$$
\begin{aligned}
& m=\frac{2 n p q-n_{2}}{2 p q\left(n-n_{2}\right)} \quad \text { with standard error } \\
& 2(1-2 \mathrm{mpq}) \sqrt{\frac{1-\mathrm{m}}{\mathrm{n}}} \\
& \mathrm{n}=\text { total pairs of twins } \\
& \mathrm{n}_{2}=\text { total pairs of unlike- } \\
& \mathrm{p}=\text { proportion of males } \\
& \mathrm{q}=1-\mathrm{p}
\end{aligned}
$$

Student $t$-tests were conducted to test the difference between means for calving traits measured within fixed factors.

Heritabilities within the three parity subclasses were estimated using a paternal half-sib covariance procedure from an analysis that included only sire effects. Only bulls appearing as maternal grandsires that had over 40 daughters calving in the survey were included in the analysis. Variance components were estimated using Henderson's Method 1 (Henderson, 1953).

\section{RESULTS AND DISCUSSION}

\begin{tabular}{|c|c|c|c|c|}
\hline \multirow[b]{2}{*}{ Parity } & \multicolumn{3}{|c|}{ Dam size } & \multirow{2}{*}{$\begin{array}{l}\text { Parity } \\
\text { ignoring } \\
\text { dam size }\end{array}$} \\
\hline & Large & Medium & Small & \\
\hline First & 1.54 & .79 & 1.39 & 1.05 \\
\hline Second & 4.10 & 4.34 & 4.50 & 4.32 \\
\hline$\geqslant$ Third & 6.02 & 6.28 & 6.34 & 6.18 \\
\hline Overall parity & 5.31 & 4.70 & 3.94 & 4.82 \\
\hline
\end{tabular}

Due to the small sample size for the nonHolstein dairy breeds, no statistical tests were done to determine if there were any breed differences, though they do appear to exist (table 1). The frequencies tend to agree with weighted averages of those reported in past literature (Hendy and Bowman, 1970; Rutledge, 1975), except for Holsteins. The average of past literature reports for the twinning rate

TABLE 3. PERCENT MULTIPLE BIRTHS BY DAM SIZE WITHIN PARITYa

\footnotetext{
${ }^{a}$ Size of dam within each parity was not significant, $P>.05$.
} 
TABLE 4. ESTIMATES OF HERITABILITY OF TWINNING FREQUENCY

\begin{tabular}{llll}
\hline & $\begin{array}{l}\text { No. of } \\
\text { Parity }\end{array}$ & $\begin{array}{l}\text { No. of } \\
\text { obser- } \\
\text { vations }\end{array}$ & $h^{2}$ \\
\hline All & 52 & 10,600 & .05 \\
First & 46 & 2,266 & .06 \\
Second & 51 & 2,812 & .03 \\
$\geqslant$ Third & 51 & 5,522 & .03 \\
\hline
\end{tabular}

in Holsteins is $3.5 \%$. The incidence of $4.75 \%$ found in this study indicates that there has been an increase in the twinning rate over the last few years, unless there has been a reporting bias. If twinning is related to nutrition and production levels, as hypothesized by Syrstad (1974a), the change in twinning rate is not unexpected considering the trends in feeding and production levels.

Table 2 summarizes the analysis of variance and supporting chi-square tests done to determine which of the fixed factors reported in the survey and thought to affect the twinning rate were statistically significant. In both analyses, parity appears to be the most important factor $(P<.05)$. In addition, the three-way interaction between dam size, parity and month of conception was significant but is difficult to interpret.

The incidence of twins by parity over month was graphed to examine the effect of month of birth (figure 1). Though no clear-cut trend exists, there is a slight peak in the twinning rate during May, June, and July. Calves born in early summer would have been conceived in September, October and November, a time of the year when pasture forage is supplemented by fresh hay, silage and grain. Cows fed on a herd basis and not as individuals begin to have more supplements added to their diet. This higher plane of nutrition for cows that happen to be open at the time may cause an increased rate of multiple ovulations, as suggested by Syrstad (1974a) and Johansson et al. (1974). In addition, the effect of parity is also evident in the figure.

Twinning rates are shown in table 3 for each dam size within parity. The parity effect is well illustrated; twinning increased from $1.05 \%$ for first calf heifers to $6.18 \%$ for cows in third and greater parities. This parity effect may be the result of one or both of two reasons. Older cows may be more likely to double ovulate than younger cows and/or younger cows are unable to maintain a biparous pregnancy and abort one or both fetuses soon after conception.

Although there is no size of dam effect within any given parity, the twinning rate increased $(\mathrm{P}<.05)$ with increasing dam size when dam size was not considered nested. However, primiparous cows comprised a much greater proportion $(37.6 \%)$ of the small dam size subclass than they did in the two larger subclasses $(18.2 \%$ of medium and $9.9 \%$ of large), making the overall estimate of size effect somewhat suspect.

There were 52 bulls which appeared in the survey as maternal grandsires to the calves and which had over 40 daughters calving. The percentage of daughters in the paternal half-sib groups giving birth to twins ranged from 0 to $15.5 \%$. Johansson et al. (1974) also found this type of variation. The mean percentage for these 52 bulls was $4.77 \pm .23 \%$. This range suggested that there might be additive genetic variation in twinning; however, heritability estimates summarized in table 4 do not support the

TABLE 5. RATIO OF TWIN TYPES AND INCIDENCE OF MONOZYGOUS TWINS

\begin{tabular}{|c|c|c|c|c|}
\hline Parity & Pairs & Ratio $\mathbf{a}, \mathbf{b}$ & $\begin{array}{l}\text { Estimate } \\
\text { of mono- } \\
\text { zygous (\%) }\end{array}$ & SE (\%) \\
\hline First & 40 & $10: 21: 9$ & -10.66 & 35.04 \\
\hline Second & 222 & $56: 113: 53$ & -3.71 & 13.92 \\
\hline$\geqslant$ Third & 721 & $185: 334: 202$ & 13.60 & 6.45 \\
\hline All & 983 & $247: 468: 268$ & 9.04 & 5.81 \\
\hline
\end{tabular}

\footnotetext{
${ }^{\text {a }}$ Male:mixed sex:female.

$\mathrm{b}_{\text {Not different from 1:2:1 (P>.05) for all groups. }}$
} 
TABLE 6. COMPARISON BY PARITY OF COW OF CALVING CHARACTERISTICS OF TWIN BIRTHS

\begin{tabular}{lllr}
\hline & & \multicolumn{2}{c}{ Parity } \\
\cline { 2 - 4 } Trait & First & Second & $\geqslant$ Third \\
\hline Calving difficulty & $1.93 \pm .22^{\mathrm{b}}$ & $1.71 \pm .08$ & $1.79 \pm .04$ \\
Vigor & $1.68 \pm .10$ & $1.60 \pm .04$ & $1.58 \pm .02$ \\
Percent dead calvesc & 25.00 & 23.36 & 23.73 \\
\hline
\end{tabular}

${ }^{\mathrm{a}} \mathrm{P}>.05$ for all traits.

$\mathrm{b}_{\text {Standard error. }}$

CBy first 24 hr postpartum.

view that additive genetic variation is large. Heritability was estimated within each parity to avoid any bias that would be introduced if any confounding with parity was introduced into the sire variation. These estimates are in agreement with those of Syrstad (1974b). Heritability estimates reported by Johansson et al. (1974) for SRB and SLB breeds were lower, especially in the case of primiparous cows.

Woelffer (1976) has reported a herd, with a higher than normal level of inbreeding, in which there has been success in genetically increasing the twinning rate. Allowing for the fact that this may be due partly to a herd effect, this indicates that there may be other types of genetic variation on which to base selection. The higher level of inbreeding indicates that full-sib matings or parent-progeny matings may have been practiced in that herd. In the case of full-sib matings, dominance genetic variation could be large enough to affect the twinning rate.

Since monozygous twins are of interest to research for various types of experiments and since the percentage of monozygous twins would influence the heritability estimates for twinning (assuming different modes of inheritance for monozygosity and dizygosity), the frequency of monozygosity was investigated.

Monozygous twins must be of the same sex; therefore the ratio of male mixed sex:female twin types should deviate from the expected 1:2:1 ratio if there are monozygous twins in the twin population. When this ratio was tested using a chi-square test, there was no significant deviation from the expected ratio in the overall twin population nor within any of the parity groups, indicating that there were very few monozygous twins (table 5).

Though the chi-square tests indicate that there were no monozygous twins in the herds studied, it is known from physiological evidence that monozygous twins do exist in cattle populations. Therefore, using the formla derived by Bonnier (1946), the percentage of monozygous twins among like-sexed twins was estimated and found to be small (table 5). Since the chi-square test was not sensitive enough to detect the occurrence of monozygous twins, it probably could not detect any parity effect

TABLE 7. COMPARISON OF SINGLE BIRTH AND TWIN BIRTH CALVING CHARACTERISTICS

\begin{tabular}{|c|c|c|c|c|}
\hline Trait & Singles & Twins & $t$ & $x^{2}$ \\
\hline Gestation length, days & $279.0 \pm .1^{\mathrm{a}}$ & $273.8 \pm .3$ & $2.468^{*}$ & $\cdots$ \\
\hline Percent males & 50.85 & 51.07 & $\cdots$ & .034 \\
\hline Calf size & $3.248 \pm .006$ & $2.359 \pm .020$ & $42.575^{*}$ & $\cdots$ \\
\hline Calving difficulty & $1.441 \pm .007$ & $1.774 \pm .039$ & $8.404^{*}$ & $\ldots$ \\
\hline Calf vigor & $1.154 \pm .004$ & $1.586 \pm .019$ & $22.249^{*}$ & $\ldots$ \\
\hline Percent mortality & 5.92 & 22.43 & $\ldots$ & $712.365^{*}$ \\
\hline
\end{tabular}

$* \mathrm{P}<.05$.

${ }^{a}$ Standard error. 
TABLE 8. EFFECT OF TWIN BIRTHS ON THE NUMBER OF AVAILABLE HEIFER REPLACEMENTS AT 1 DAY OF AGE

\begin{tabular}{|c|c|c|}
\hline Item & Single births & Twin births \\
\hline $\begin{array}{l}\text { Given } \\
\text { Effect of monozygosity }{ }^{a} \\
\text { Effect of sex ratiob } \\
\text { Losses from neonatal mortality } c \\
\text { Losses from infertility }\end{array}$ & $\begin{array}{l}1000 \text { births } \\
1000 \text { calves } \\
492 \text { female calves } \\
469 \text { female calves } \\
469 \text { fertile females }\end{array}$ & $\begin{array}{l}1000 \text { pairs } \\
48 \text { monozygous pairs }+952 \text { dizygous pairs } \\
252 \text { female pairs }+466 \text { mixed pairs } \\
396 \text { females } e+361 \text { females } \\
396 \text { females }^{e}+36 \text { females }\end{array}$ \\
\hline Net results & 469 fertile females & 432 fertile females \\
\hline
\end{tabular}

\footnotetext{
${ }^{2} 4.75 \%$ of all twins.

$\mathrm{b}_{49.15}$ \% females in single and monozygous twin births and $48.93 \%$ females in dizygous births.

$c_{4.67 \%}$ among single females, $21.52 \%$ among females twin pairs and $22.46 \%$ among mixed twin pairs.

${ }^{d}$ Assumed $0 \%$ for single females and females born cotwin to females, and $90 \%$ for females born cotwin to a male.

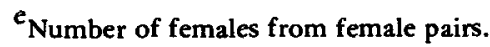

$f_{\text {Number of females from mixed pairs. }}$

$\mathrm{g}_{\text {Reduced to }} 396$ if all 361 females born cotwin to a male are culled.
}

either. Using Bonnier's (1946) formula, the percent of like-sexed twins that were monozygous was estimated for each parity group to investigate parity differences. In table 5 , estimates for the first and second parity groups are not acceptable and must be assumed to be zero. The trend shown would suggest that there may be a parity (age of dam) factor affecting monozygous twinning. However, since the number of monozygous twins is so small, the effect parity has on monozygous twinning is probably only a contributing factor to the effect parity has on the overall twinning rate and not the causative factor.

These results concerning monozygotic twinning are contradictory to the report by Johannson et al. (1974). Admittedly the sample size is smaller in this study. With a larger sample size, the negative estimates of monozygotic twinning rates for first and second parity cows probably would not be zero.

Having examined the factors affecting twinning, the effect that twins have at calving time was investigated. The ability of the three different parity groups to give birth to twins is summarized in table 6 . There were no differences $(P>.05)$ between the three parity groups for calving difficulty. However, there were only 40 first-calf heifers that had twins compared to 219 and 731 for the other two groups. In addition, there were no differences $(P>.05)$ between the three groups for the average vigor scores or for mortality rates by $24 \mathrm{hr}$ postpartum.

Differences between calving traits for monoparous and biparous births are presented in table 7. Gestation length was 5.2 days shorter $(\mathbf{P}<.05)$ for twins than for singles. There was no difference $(P>.05)$ between the sex ratios at birth. The three important calving traits, calf size, dystocia, and calf vigor, were all affected by twinning in a negative sense $(P<.05)$. Calf size was reduced by almost one classification unit, probably due somewhat to the shorter gestation length. Contrary to what might be expected when considering the smaller size of twins, dystocia increased, probably because of complications arising from competition between the two fetuses to be born first. As would be expected when there is dystocia, a shortened gestation period and a smaller calf, twins were weaker and had a mortality rate that was almost four times as great as singles.

Pfau et al. (1948) suggested that there is a decrease in the number of fertile females with twins; however, no estimate of this decrease was reported. To quantify this decrease, if there is one, the number of fertile females available as replacements at one day of age in this study was estimated using parameters estimated from this survey. A summary of the procedure is outlined in table 8 . The net result is that there was an $8 \%$ reduction in the number of available females per 1,000 twin birth as compared to 
1,000 single births. The reduction is caused by the higher mortality rate of twins and the occurrence of freemartins in mixed sets of twins. In addition, most dairymen are unwilling to pay the cost of determining which of the 361 females born cotwin to a male are fertile. Therefore, all would usually be culled, further reducing the number of replacement females from twins to 396 , a $15 \%$ reduction. In an operation where a high percentage of the females born must be kept, a reduction in the number available severely reduces the ability for genetic improvement from maternal selection.

\section{CONCLUSIONS}

Apparently the benefits of twinning in Holstein herds cannot be taken advantage of without some cost, at least at parturition. Part of this cost would be the fewer number of females available as replacements, slowing down genetic progress in other traits involved in a selection program, such as milk production.

In addition, selection for twinning would appear to be difficult and time consuming, in agreement with the conclusion of Syrstad $(1974 \mathrm{~b})$, because there is little additive genetic variation and because the parity effect increases the time needed to select foundation stock and replacements with which to start a program. The amount of time and money spent would add to the cost of increasing the twinning rate, making it very difficult for the attainment of a high-incidence twinning herd to be a profitable undertaking.

Considering these two problems, twinning does not appear as desirable as might be believed for the Holstein breed. Further study is needed to assess the effects of twinning on subsequent lactation production and reproduction to determine whether twinning has any advantages other than for producing more veal calves.

\section{LITERATURE CITED}

Bonnier, G. 1946. Studies on monozygous cattle twins. II. Frequency of monozygous twins. Acta Agr. Suecana, I. 2:147.

Cady, R. A. 1977. Dystocia and related calving traits in dairy cattle. Master's Thesis. Cornell University, Ithaca, NY.

Henderson, C. R. 1953. Estimation of variance and covariance components. Biom. 9:226.

Hendy, C. R. C. and J. C. Bowman. 1970. Twinning in cattle. Anim. Breed. Abstr. 38: 22.

Johansson, I., B. Lindhé and F. Pirchner. 1974. Causes of variation in the frequency of monogygous and dizygous twinning in various breeds of cattle. Hereditas. 78:201.

Pfau, K. D., J. W. Bartlett and C. E. Short. 1948. A study of multiple births in a Holstein-Friesian herd. J. Dairy Sci. $31: 241$.

Rutledge, J. J. 1975. Twinning in cattle. J. Anim. Sci. 40:803.

Snedecor, G. W. and W. G. Cochran. 1967. Statistical Methods (6th Ed.). Iowa State College Press, Ames.

Syrstad, O. 1974a. Relationship between twin births and milk production in dairy cattle. Meldinger fra Norges Landbruksh $\phi$ gkole. Vol. 53, No. 5.

Syrstad, O. 1974b. Genetic aspects of twinning in dairy cattle. Acta. Agr. Scand. 24: 319.

Woelffer, E. A. 1976. Aborted twins at 43 days. Hoard's Dairyman. 121:573. 